\title{
A Bioética teológica e a sua pertinência no debate social atual
}

\author{
The Theological Bioethic and its relevance \\ in the current social debate
}

\section{Evandro Arlindo de Melo ${ }^{[a]}$, Mário Antônio Sanches ${ }^{[b]}$, María del Carmen Massé García ${ }^{[c]^{*}}$}

\author{
[a] Instituto Sapientia de Filosofia, Francisco Beltrão, PR, Brasil \\ [b] Pontifícia Universidade Católica do Paraná, Curitiba, PR, Brasil \\ [c] Universidade Pontifícia de Comillas, Madri, Espanha
}

\section{Resumo}

O presente artigo aborda a presença da Teologia no contexto da Bioética. O objetivo do texto é identificar as tensões entre as duas áreas, mapear historicamente a contribuição da Teologia para a nova disciplina e a possibilidade de falar de uma bioética teológica. A pesquisa bibliográfica e documental demonstra que a reflexão teológica influenciou no surgimento da Bioética, tanto numa preparação remota como em contribuição 
mais específica no início da segunda metade do século XX. Deste modo, destaca-se que as duas disciplinas podem se enriquecer entre si, desde que as contribuições recíprocas mantenham uma postura dialogante e respeitosa. Conclui-se que é possível falar de bioética teológica na medida em que a reflexão teológica compreenda o caráter secular e plural próprio da Bioética.

Palavras-chave: Teologia. Bioética. Sociedade.

\section{Abstract}

This article discusses the presence of theology in the context of bioethics. The objective of this text is to identify tensions between the two areas, map historically Theology's contribution to the new discipline and the possibility of speaking of theological bioethics. Bibliographic and documentary research demonstrates that the theological reflection influenced the emergence of Bioethics both in a remote preparation as in more specific contribution early in the second half of the 20th century. Thus, we highlight that the two disciplines can enrich each other since reciprocal contributions maintain a dialogue and respectful posture. It is concluded that it is possible to speak of theological bioethics since the theological reflection understands the secular and plural character of Bioethics.

Keywords: Theology. Bioethics. Society.

\section{Introdução}

Este artigo coloca em debate a Bioética Teológica, o que implica em algumas dificuldades e desafios, principalmente em uma sociedade plural e secular. A dificuldade maior está exatamente em justificar a necessidade e possibilidade de se estabelecer uma reflexão dessa natureza no atual debate social bioético.

Este problema adquire ainda maior profundidade porque para a Teologia poder ter realmente uma voz dentro da reflexão bioética, ela 
não só deve procurar seu espaço neste debate, mas também, deve superar o desafio de se abrir. Isto implica em não se tornar um pensamento arrogante e dogmático e, ao mesmo tempo, não perder a sua identidade, construída a partir da tradição religiosa que representa.

Para discorrer sobre esta temática, convém iniciar pelo questionamento de Alasdair MacIntyre, que desafia os teólogos a demonstrarem que sua disciplina não é uma mera superstição, mas ao contrário, uma reflexão que realmente traz benefícios para o contexto da discussão da Bioética. Como se refere o autor: "Os teólogos ainda devem isso para o resto de nós, explicar por que não devemos tratar a sua disciplina como fazemos com a astrologia ou frenologia" (MACINTYRE, 1979, p. 443).

Tentando responder a este questionamento, José Vico Peinado escreve um artigo que foi publicado na revista Moralia, onde o título deste, nada mais é, do que a pergunta: “¿Cabe hablar de 'Bioética Teológica?” (VICO PEINADO, 2003, p. 439), o que remete a tentar estabelecer a pertinência deste tipo de reflexão, ou se a mesma é, como afirma A. MacIntyre, uma forma de superstição.

Para o autor do artigo da Revista Moralia, esta reflexão precisa ser desenvolvida e deve partir não só de quem questiona a presença da Teologia no debate bioético, mas sobretudo, deve ser concretizada, primeiramente, por aqueles que realizam a reflexão bioética dentro da perspectiva teológica, pois para ele:

[...] el teólogo tiene que preguntarse hasta qué punto tiene una palabra propia, adecuada y pertinente que decir en este campo. Es decir, quitando personalismos y elevando la problemática a niveles teóricos, tiene que preguntarse hasta qué punto se puede hablar y con qué sentido de bioética "teológica". Ha de cuestionarse si no habrá que rechazar el adjetivo (teológica) en función del estatuto epistemológico del sustantivo (bioética) (VICO PEINADO, 2003, p. 453-454).

Esta análise que deve realizar o teólogo a si mesmo e a partir de dentro da própria reflexão que desenvolve, a saber, desde uma adjetivação teológica da Bioética, é considerado pelo próprio J. Vico Peinado, antes de tudo, como uma questão de direito, objetivando que aqueles que são da área da Teologia possam garantir o seu lugar dentro da reflexão bioética: 
De todas formas, el planteamiento al que me refiero no suscita una cuestión de hecho, sino de derecho. Me pregunto, ante todo y sobre todo, con qué derecho y en qué sentido se puede adjetivar como "teológica" una ciencia como la "bioética", que tiene una vocación cívica y secular, cuya reflexión es autónoma y racional y que metodológicamente intenta servirse de criterios operativos para resolver responsablemente problemas concretos, más allá de los grandes planteamientos ideológicos (VICO PEINADO, 2003, p. 455).

Diante disto, busca-se afirmar que atualmente é possível falar em Bioética Teológica. Uma exposição completa desta possibilidade requer muitos elementos de modo que, neste artigo, queremos apresentar alguns aspectos que podem se somar a outros na construção do argumento central: a Bioética Teológica é necessário no amplo contexto da Bioética atual. Para se dar esta contribuição, em busca de atingir este objetivo e sanar a problemática aqui apresentada, se opta: primeiramente, por resgatar a perspectiva histórica da Bioética, onde se percebe que esta nasceu ligada à Teologia; e, em um segundo momento, por procurar estabelecer a importância da Teologia para o debate social em bioético.

\section{Interfaces históricas da relação entre bioética e teologia}

Busca-se aqui demonstrar que, no que diz respeito às questões históricas, tanto no período que antecedeu, quanto no período de nascimento da Bioética, é que a Teologia tem uma presença marcante em ambos os momentos, ficando difícil até mesmo de definir as fronteiras entre estas duas áreas de saber.

Embora não se tenha por intento aqui resgatar toda a realidade histórica dessa relação, algumas questões são importantes, a começar pelo período que antecedeu o nascimento da Bioética, onde é possível afirmar que as questões teológicas já refletiam as futuras questões que seriam abarcadas pela Bioética.

Das muitas perspectivas que aqui poderiam ser analisadas, talvez seja importante começar por aquilo que se estabeleceu no que diz respeito à área médica, em que se centram as principais questões bioéticas. Podese dizer que desde os princípios da Medicina, já havia a preocupação dos cristãos para com as mesmas questões que esta área suscitava, bastando relembrar Javier de la Torre: 
D. Verhey afirma con claridad que antes que la ética médica fuera un campo distinto da reflexión, "los cristianos y otros con convicciones religiosas estaban comprometidos con las cuestiones Morales planteadas por la atención médica, tratando de responderlas de forma apropiada a la forma como ellos hablaban de Dios" (DE LA TORRE, 2008, p. 14).

Fica claro com esta postulação, que os médicos cristãos se preocupavam com os problemas que estavam diante deles, tentando interpretá-los à luz dos valores trazidos pelas suas crenças religiosas. Não por acaso, o próprio J. de la Torre continua a refletir: "Muchos médicos intentaban sinceramente integrar sus creencias religiosas com suvocación médica" (DE LA TORRE, 2008, p. 14).

Se esta preocupação afetava os médicos cristãos, quanto mais aqueles que se dedicam a pensar e a refletir a Teologia diante destas questões éticas e morais. Sobre isso, Albert R. Jonsen, em seu breve tratado sobre a história da Medicina, refletindo sobre a Teologia Católica, afirma que: "Durante el siglo XV los teólogos católicos desarrollan una rama especial de La Teología que se centraba en las obligaciones Morales de los cristianos. Estos nuevos teólogos Morales analizaron con meticuloso detalle los distintos estados de la vida" (JONSEN, 2011, p. 130).

Aprofundando essa proposição, afirma Javier Gafo:

El interés de la Moral de la Iglesia Católica por los temas de Bioética ha sido importante en su historia. Los grandes autores de la Teología Moral católica han abordado una serie de temas que siguen constituyendo hoy una parte importante dentro de las actuales publicaciones de Bioética. Desde el siglo XIX comienzan a aparecer algunas publicaciones católicas dedicadas monográficamente a los problemas clásicos de moral médica, una línea que se mantiene a lo largo de la primera mitad del siglo XX (GAFO, 1988, p. 119).

Diante disso, voltando a A. R. Jonsen, o autor justifica o nascimento e a importância de algumas dessas obras nos Estados Unidos, postulando que:

[...] al mismo tiempo que el sistema de atención sanitaria con patrocinio católico crecía en proporciones considerables, los teólogos aportaron a los 
médicos y enfermeras católicas, a clérigos y a pacientes, una serie de guías encaminadas hacia un pensamiento doctrinalmente correcto sobre cuestiones de medicina (JONSEN, 2011, p. 235).

Com base ao que foi postulado, convém destacar três obras teológicas que se destacaram no período que antecedeu a Bioética, a saber:

- Moral Principles and Medical Practice: The basis of American Jurisprudence $^{1}$ (COPPENS, 1897): do padre católico Charles Coppens, que apresenta uma argumentação ética e ensinamentos religiosos no que diz respeito a questões ligadas ao aborto, a eugenia, a eutanásia e ao uso de alguns tipos de fármacos;

- Physician, Pastor and Patient: Problems in Pastoral Medicine ${ }^{2}$ (JACOBY, 1936): do Dr. George Jacoby, sendo uma obra não confessional onde todos, pastores, médicos e pacientes, podem buscar iluminações sobre problemas éticos relevantes;

- Ethical Basis of Medical Care ${ }^{3}$ (SPERRY, 1950): do então decano da Faculdade de Teologia de Harvard, Williard Sperry, que foi resultado de um convite do Dr. James Means, chefe do serviço médico do Massachusetts General Hospital (MGH), para realizar uma palestra ao pessoal médico do Hospital sobre problemas que estaria enfrentado na ocasião, em especial, quando o médico não tinha mais o que fazer ao problema apresentado por seus pacientes e que se cobrava uma atitude do mesmo. Sobre W. Sperry, A. R. Jonsen afirma que foi um dos pioneiros na literatura da ética médica, considerando que ele: "[...] fue uno de los primeros no profisionales de la medicina y uno de los primeros teólogos que contriuyeron a uma literatura que había sido del domínio casi exclusivo de los médicos" (JONSEN, 2011, p. 238). Como se pôde perceber com tudo isso, foi notória a presença da reflexão teológica no período antecedente ao nascimento da Bioética, sendo os teólogos, os primeiros a escreverem e lecionarem ética médica, pois como bem recorda G. Durant: "Na primeira metade do século XX, a

\footnotetext{
"Princípios Morais e Prática Médica: As bases da Jurisprudência Americana" (tradução livre).

"Médico, Pastor e Paciente: Problemas na Pastoral Médica" (tradução livre).

"Bases Éticas do Cuidado Médico" (tradução livre).
} 
maior parte dos autores e docentes de ética médica eram teólogos, pastores ou rabinos" (DURANT, 2007, p. 26).

Não obstante a isto, é notória também que esta presença da Teologia foi contundente no nascimento da Bioética e nos anos que sucederam este nascimento. Esta mesma presença não pôde ser considerada estranha à forma como a fé cristã aborda as relações com as ciências e com a cultura de cada época, pois segundo J. Gafo:

[...] la experiencia religiosa es una llamada al compromiso ético. Es lo que se refleja en el comienzo del cristianismo, en la primera predicación apostólica, cuando los primeros creyentes, tras haber expresado su opción de fe religiosa, dan inmediatamente el salto a la pregunta ética: "Que tenemos que hacer, hermanos?"4 (GAFO, 2003, p. 91).

Sendo assim, é possível afirmar que a presença da Teologia foi imprescindível ao nascimento da Bioética, tornando-se relevante recordar, mais uma vez, J. de la Torre, que afirma: “[...] entre 1965 y 1970, en el 'renacimiento de la ética médica', y en la primera década de la bioética (19711980), los pensadores religiosos jugaron papel importante" (DE LA TORRE, 2008, p. 15) e, como exemplo, o autor relembra da chamada National Commision dos Estados Unidos, que no ano de 1974 dos sete assessores em ética que ali estavam presentes, cinco eram justamente oriundos da vertente de reflexão da ética teológica ${ }^{5}$.

Esta proposição é compartilhada por José Roque Junges que enfatiza não só o fato de que os teólogos marcaram presença importante neste período da Bioética, mas também, esclarece porque esta se deu com tanta competência. Segundo o autor: "Os teólogos desempenharam um papel importante no surgimento da Bioética, devido à experiência na argumentação ética para solucionar casos e, especialmente, à tradição de intervenções em ética médica" (JUNGES, 2006, p. 51).

4 Cf. Atos 2,37.

5 Estes cinco teólogos são, respectivamente, Fletcher, McCormick, Ramsey, Siegel e Walters. Os três primeiros têm um papel especial no surgimento e desenvolvimento da reflexão bioética que será explicitado posteriormente. 
Levando em consideração a presença significativa de tantos teólogos que tiveram participação ativa e influente no surgimento e nos inícios da Bioética, sejam com seus pensamentos, seja com a publicação de inúmeras obras, torna-se relevante retomar A. R. Jonsen. O referido autor, em seu grande tratado de História da Bioética, intitulado "The Birth of Bioethics" (JONSEN, 1998), dedica o segundo capítulo, denominado por ele como "The Theologians: Rediscovering the Tradition", à explicitar a participação dos teólogos no nascimento desta disciplina. Neste capítulo, o autor reflete sobre o que ele chama de "A Trinity of Theologians", fazendo parte desta trindade, os teólogos: Joseph Fletcher (1905-1991); Paul Ramsey (1913-1988); e Richard A. McCormick (1922-2000). Sobre estes teólogos, A. R. Jonsen não só afirma a importância no início da Bioética, mas postula que os três presidiram a criação desta disciplina. Eis a importante assertiva do autor:

Três teólogos presidem a criação da Bioética: Joseph Fletcher, um ministro Epicopal; Paul Ramsey, um professor Metodista; e Richard McCormick, um teólogo moral jesuíta. Esta Trindade, ao contrário da Trindade Divina da teologia cristã, não era "una e indivisível", mas em vez disso, formou um espectro de opinião que variou do Fletcher liberal e ao conservador Ramsey, com McCormick no meio deles como um moderado. Cada um representa sua tradição teológica de forma única; cada qual fez contribuições intelectuais importantes para a formulação de questões bioéticas, às vezes formulando substantivas posições que têm sofrido, em vários momentos, perspectivas contrastantes dentro das quais o debate subsequente tem continuado (JONSEN, 1998, p. 41-42).

Não obstante a esta participação inquestionável dos teólogos no nascimento e nos primeiros anos de desenvolvimento da Bioética, certo foi, que passados os primeiros anos de uma relação saudável, esta acabou passando por um momento delicado quando a reflexão bioética sofreu um processo de secularização, questionando a pertinência da Teologia em seus debates sociais. Este processo de secularização gerou um distanciamento da Bioética com a Teologia, que já se começou a ser constatado, ainda na

\footnotetext{
6 “Os Teólogos: Redescobrindo a Tradição" (tradução livre).

7 "A Trindade de Teólogos" (tradução livre).
} 
primeira década de existência da reflexão bioética, ou seja, na década de 70 do século XX (DE LA TORRE, 2008, p. 19). O autor aprofunda esta situação de decadência da participação teológica na Bioética, postulando que "En los años 70 descienden los trabajos de especialistas procedentes de las religiones y comienzan a adquirir mayor relevancia los temas de la paz y los derechos humanos. Los juristas y filósofos son preferidos a los teólogos" (DE LA TORRE, 2008, p. 15).

O que se percebe com tudo isso, é que a partir de então, os debates bioéticos se desenvolvem em uma realidade onde se questiona o que J. Gafo chamou de um "código único" da ética, e onde se tenta estabelecer, segundo os conceitos do mesmo autor, um "código múltiplo". Isso faz com que se entenda que o processo de secularização da Bioética, e o consequente afastamento da reflexão teológica e daqueles que a levavam adiante, a saber, os teólogos morais das mais diversas tradições religiosas, se deu, segundo J. Gafo, porque:

[...] una temática que anteriormente estaba dominada por la medicina y la tradición religiosa, aparece ahora dominada por conceptos filosóficos y legales. La consecuencia ha sido enfatizar temas seculares: los derechos humanos, la autonomía, la justicia, al mismo tiempo que predomina la negación sistemática de la existencia de un bien transcendental individual (GAFO, 2003, p. 75).

Diante dessa realidade, acaba se suspeitando que a participação dos teólogos possa realmente trazer benefícios à reflexão bioética. Por causa disso, instaura-se um clima de verdadeira intimidação destes pensadores, fazendo com que os mesmos tomassem uma atitude no mínimo surpreendente no que diz respeito às suas participações nos debates sociais: os teólogos morais, nestes momentos, deixavam de lado, ou melhor, não manifestavam publicamente suas convicções religiosas e as suas opções éticas e morais a partir da confessionalidade. Isso tudo aconteceu, ainda segundo J. Gafo, porque:

En todo este clima, se intimidaba a la religión para que no expresase su voz o la restringiese a los confines de las comunidades religiosas particulares. Las mismas personas religiosas tenían temor de expresar sus convicciones 
en los foros públicos y consideraban que, para ser aceptados en los mismos, debían hablar el lenguaje común, ocultando sus propias opciones éticas, que permanecían como agendas ocultas (GAFO, 2003, p. 78).

Tomando os teólogos essa atitude, é claro que se tornou inevitável um distanciamento histórico entre a Teologia e a Bioética, sendo que, ainda segundo o autor aqui referenciado, se pode perceber que: " $\mathrm{La}$ consecuencia de esta actitud general es que se empujaba hacia una forma de filosofía moral que aspiraba a una especie de neutralidad despegada (Nagel la llamó the view from nowhere) y a un universalismo racionalista, libre de sus raices culturales" (GAFO, 2003, p. 78).

Diante de tudo isso, convém uma análise de que, se depois de processo de secularização, ainda é conveniente falar em Bioética Teológica e, havendo esta possibilidade, refletir em que sentido ela enriquece o debate social.

\section{A importância da Teologia para um debate Bioético}

A Bioética é marcadamente um espaço interdisciplinar, deste modo é enriquecida pela contribuição dos outros saberes e será mais rica quanto mais aberta, dialogante e compreensiva for. Esta característica da Bioética já seria suficiente para justificar o espaço da Teologia neste debate, ao lado de outras áreas do conhecimento. Todavia é fundamental explicitar o que a Bioética perde ou ganha incorporando a reflexão teológica. Iniciamos com a questão de que um debate social que não tenha uma relação saudável entre a Bioética e a Teologia é visivelmente mais pobre do que um debate que tenha esta boa relação. Faz-se necessário aqui recordar a proposição de Daniel Callahan que após questionar se a Teologia tem algo a oferecer à reflexão bioética, analisando a relação da ética biomédica e as proposições religiosas, ele chega à conclusão que a ética biomédica não é mais robusta nem satisfatória se abandonar a teologia. (CALLAHAN apud DE LA TORRE, 2008, p. 22).

Esta postulação, proferida por um grande bioeticista, já coloca por si só a necessidade de se considerar o elemento teológico dentro do debate 
social bioético. No entanto, pode-se ir um pouco além, J. Gafo reflete sobre esta questão e, estabelece alguns elementos efetivos do que acontece com uma Bioética que não se deixa questionar e influenciar pelas proposições e pela reflexão teológica. $\mathrm{O}$ autor cita três tendências que podem ocorrer com a Bioética, caso ela se afaste da Teologia, tendências estas vistas como empobrecedoras, a saber:

1. Crea una exagerada dependencia de la ley como fuente de moralidad. Lo que dicen los tribunales y las legislaturas es lo que determina lo que está bien o mal, lo que está permitido o prohibido;

2. Priva de la sabiduría y de los conocimientos acumulados, que son fruto de las tradiciones religiosas establecidas hace mucho, ya que, como dice el mismo autor, no hace falta ser judío o cristiano para valorar lo que han aportado esas tradiciones;

3. Y, en tercer lugar, induce a creer que no pertenecemos a comunidades morales particulares y, lo más llamativo, es que se celebra este hecho como expresión de pluralismo. Sin embargo, "este pluralismo se convierte en una forma de opresión, en su mismo nombre, ya que se nos dice que hay que callar en público sobre nuestras vidas o creencias privadas y hablar, como dice Jeffrey Stout, una forma de esperanto moral (GAFO, 2003, p. 79).

Assim, fechando-se à reflexão teológica, que nasce das diversas tradições religiosas, cria-se uma pretensa comunidade secular uniforme com riscos à excluir e segregar a diversidade moral legítima de nossas sociedades. Evidencia-se, deste modo, o dano de uma Bioética que prescinda da reflexão teológica, mesmo porque, além da Teologia ser pertinente para o debate social por toda a sabedoria que lhe é própria e que foi adquirida durante milênios de desenvolvimento histórico, esta pode ajudar a reflexão bioética a não incorrer em erros que poderiam lhe afastar de cumprir sua tarefa que se torna primordial na sociedade atual, de características plural e secular.

É evidente que da parte da Teologia, esta deve reconhecer humildemente que no debate social, não terá soluções prontas para vários problemas que serão apresentados pela Bioética. Sobre isto, o Papa Bento XVI, em um discurso proferido para a Congregação para a Doutrina da fé, em 31 de Janeiro de 2008, lembrava que a Igreja, em especial, o seu Magistério, não tem o direito de interferir em todas as 
questões relacionadas ao desenvolvimento tecnológico, principalmente às novidades trazidas pelas Ciências. Seu papel é apenas de recordar aos homens e mulheres os valores e o que ele chama de "orientações éticomorais". Na assertiva do Papa:

O Magistério da Igreja certamente não pode e não deve intervir sobre todas as novidades da ciência, mas tem a tarefa de afirmar os grandes valores em jogo e de propor aos fiéis e a todos os homens de boa vontade princípios e orientações ético-morais no que se refere às novas questões importantes (BENTO XVI, 2008).

Salientando sobre este não posicionamento em todas as questões modernas trazidas pelas Ciências como fruto do desenvolvimento tecnológico, é preciso esclarecer que isto nem lhe é esperado, o que não quer dizer que sua reflexão deixe de ter relevância quando estas questões vêm à tona, pois segundo $\mathrm{V}$. Coutinho:

A teologia e a ética teológica não têm uma resposta preparada para todas as grandes questões da humanidade, mas têm uma experiência e uma tradição, uma sabedoria e uma vivência, que permitem abordar estas questões de forma mais profunda, e proporcionam concepções e explicações nas quais se podem integrar estas perguntas e que são iluminadoras da razão ética que nos move (COUTINHO, 2006, p. 213).

Ainda em relação a isto, é importante afirmar com J. Gustafson, que "[...] o valor dos conceitos religiosos para a bioética não é oferecer as respostas que todos devem aceitar, mas levantar as perguntas que inevitavelmente todos devemos abordar" (GUSTAFSON apud COUTINHO, 2006, p. 213).

Esclarecendo ainda mais o papel da Teologia para a reflexão bioética, Coutinho salienta que dentro das tradições religiosas existe uma consciência de que todos devem ter uma atitude profética frente às situações que lhes são apresentadas. Para o autor, esta atitude tornase fundamental num debate como este, uma vez que ele não só expõe interesses velados e menosprezados, como também traz um lado crítico que é fundamental para que não se fique apenas num discurso "politicamente correto", o que para a ética, é algo extremamente pobre. 
Assim analisa V. Coutinho, o que considera esta atitude profética, que nasce, evidentemente, das próprias tradições religiosas:

Nas tradições religiosas fala-se de uma atitude profética, que põe em causa sistemas estabelecidos, traz à luz do dia interesses menosprezados, clama por direitos alienados, integra no debate sujeitos excluídos e aborda temas esquecidos. Este lado crítico da ética teológica leva-a a ser consciência questionante dos consensos gerados e a ter uma agenda de reflexão não marcada pelo politicamente correto (COUTINHO, 2006, p. 210).

Alguns podem apontar que a própria ideia "visão profética" já se seria uma posição exclusivamente, que ao invés de possibilitar um auxílio, dificultaria a proposição teológica no debate bioético. Para esclarecer a isto, talvez seja importante recordar o que afirmam Andrea Vicini e James F. Kennan em um artigo denominado "O futuro da Bioética" (VICINI; KENNAN, 2011), publicado na Revista Bioethikos, do Centro Universitário São Camilo. Segundo os autores, se pode postular que:

Embora central na Bíblia e na reflexão teológica tradicional, a visão profética não tem apenas conotação religiosa. Nós a consideramos principalmente uma capacidade humana. Enquanto tal, ela se torna um "lugar" privilegiado em que o divino se encontra conosco e, de maneira recíproca, encontramos o divino em nossas experiências diárias. A Bíblia ilumina as dimensões antropológicas e relacionais na profecia (VICINI; KENNAN, 2011, p. 16).

Seguindo o pensamento dos autores, convém aqui considerar outros dois pontos que por eles são elencados e que se tornam pertinentes nesta reflexão. O primeiro, em relação à questão moral mais abrangente, diz respeito ao que representa uma pessoa com uma visão profética, pois esta pessoa, além de trazer benefícios no sentido de indicar rumos para a vida dos indivíduos e da sociedade, é capaz de alimentar o caráter moral e de dar os primeiros passos no sentido de perseguir os objetivos que esta mesma visão propõe como fundamentais. Para eles:

Uma pessoa com visão profética nos indica o objetivo que merece ser perseguido tanto pelos indivíduos como pela sociedade e mostra o que é obrigatório para o agente moral em termos de caráter moral e de escolhas 
específicas. Além disso, é uma pessoa realista, que aponta ao menos alguns meios de que é preciso dispor para alcançar o objetivo em questão. Por fim, ela dá os primeiros passos para tornar concreta essa visão (VICINI; KENNAN, 2011, p. 16).

O segundo ponto traz uma referência explícita à Bioética, que deveria ser concretizada sempre como um apelo para que os bioeticistas não deixem de serem esses profetas quando realizam suas reflexões e quando participam de debates que exponham questões fundamentais para a vida do ser humano. Assim, estarão não só refletindo sobre o bem, mas promovendo este mesmo bem, sendo que:

[...] a bioética deve fortalecer em nós um caráter profético, fazemos uma ousada afirmação: pedimos aos bioeticistas a disposição imediata para formular propostas eticamente significativas, não importando quais sejam os riscos para o progresso biotecnológico. Isso pressupõe que sejamos capazes de viver de maneira ética abordando e solucionando todas as questões éticas que emergem e que identificamos. E implica que nos esforçaremos para promover o bem de todo agente moral e do mundo como um todo (VICINI; KENNAN, 2011, p. 16).

Com isso, não só se enriquece a reflexão bioética, mas a própria Teologia sai fortalecida. Sobre isso, convém recordar os elementos assinalados por J. Gafo, que fala das contribuições que a Bioética, no debate social, pode trazer para as tradições religiosas, para a reflexão teológica e para os chamados bioeticistas religiosos.

- En contra de la tendencia de las tradiciones religiosas a dar soluciones nítidas y tajantes, los debates de Bioética han ayudado a percibir la gran dificultad de los temas y de las implicaciones personales y éticas existentes. Este hecho ha ayudado a los bioeticistas religiosos a asumir posicionamientos más humildes.

- En la misma línea, el amplio debate bioético de los últimos años ha hecho comprender a los bioeticistas religiosos la inherente complejidad de los problemas implicados. De esta forma se puede eludir el peligro de la tendencia al simplismo, al esquematismo, dentro de la reflexión religiosa. 
- La historia reciente de la Bioética, con su énfasis en la necesidad de un discurso racional, debe incitar a las religiones a evitar el peligro de fundamentalismo.

- La Bioética, con su énfasis en el valor de la autonomía de la persona y la búsqueda en común de la verdad, ayuda a superar el peligro del autoritarismo.

- La Bioética, al tomar como punto de partida el valor de los datos científicos implicados, ayuda a obviar el peligro de abstruismo.

- La Bioética, al distinguir entre unos principios éticos mínimos y jurídicamente exigibles y otros que únicamente son de gestión privada y tienen un valor excelente, pero exhortativo, ayuda a evitar el peligro de la intolerancia (GAFO, 2003, p. 97).

O autor aprofunda esta reflexão, assinalando a importância das religiões que é fundante para a Bioética no que diz respeito à questão dos seus princípios, que em última instância, tem a peculiaridade de dar soluções racionais e pacíficas aos conflitos morais e éticos. Usando as palavras do próprio J. Gafo: “También las religiones pueden tener un gran valor en relación con los principios de Bioética, que han tenido una gran relevancia para dar soluciones pacíficas y racionales a los conflictos morales de una cultura plural"' (GAFO, 2003, p. 89-90).

Esta proposição é corroborada por M. Vidal, quando postula que: "Los problemas éticos de la biomedicina pueden ser considerados desde los parámetros de la racionalidad humana. Es lo que hace la disciplina de bioética racional. Pero también pueden ser planteados desde los presupuestos de la ética teológica" (VIDAL, 2011, p. 118).

Em sendo assim, para superar toda e qualquer tensão que ainda possa existir no que diz respeito à possibilidade da Bioética Teológica se fazer presente nos debates sociais sem aquela desconfiança que por muito tempo persistiu e que, em alguns casos, continua a persistir, tornase necessário recorrer mais uma vez a M. Vidal, pois o autor afirma que:

Muchas de las tensiones de la moral en el campo de la bioética se solucionarían con mejor coherencia y con mayor facilidad si se tuviera una 
comprensión exacta de la identidad, de las posibilidades y de los límites de la bioética teológica. Para conseguir esta comprensión es imprescindible analizar dos cuestiones fundamentales: la identidad epistemológica de la bioética teológica y su presencia pública en el común diálogo en una sociedad pluralista y democrática (VIDAL, 2011, p. 115).

Além destes elementos assinalados, poderiam, ainda, ser elencados muitos outros benefícios que a reflexão bioética pode trazer à reflexão teológica, justificando a sua pertinência no debate social. No entanto, estes bastam para ser esclarecido como a principal questão aqui aventada, a saber, que por tudo o que foi exposto, torna-se evidente que não só é possível falar de uma Bioética com adjetivação teológica, como também é necessário levá-la adiante, a fim de enriquecer o debate social bioético, realizado em uma sociedade plural e secular.

\section{Considerações finais}

Por tudo o que foi analisado até agora e por perceber que a Bioética Teológica tem essa capacidade de estabelecer um compromisso ético iluminado pela razão, enfatiza-se o fato que o elemento teológico não pode ficar de fora de toda e qualquer questão que envolva o ser humano, inclusive da reflexão da Bioética, que tem por objeto precípuo estabelecer, como queria Van Rensselaer Potter, uma ponte entre as ciências naturais — da saúde - e as ciências humanas (POTTER, 2016).

A presença da Teologia no debate social realizado pela Bioética, mesmo para uma sociedade plural e secular, é possível e pertinente, pois segundo J. Gafo:

De la misma forma que, en el campo de la experimentación y del desarrollo tecnológico, se ha llegado a la convicción de que no se le puede calificar como 'wertfrei', 'libre de valores', también debe reconocerse que no existe una aportación a los temas de Bioética que sea 'traditionfrei', 'libre de tradiciones' (GAFO, 2003, p. 94-95).

Seguindo a isto, não se pode ter dúvidas sobre a questão proposta neste artigo, a saber, se, atualmente, cabe falar — ou não — em Bioética 
Teológica. Tanto por parte da própria Bioética, como e principalmente por parte da Teologia, em especial da Teologia Moral, não se tem a possibilidade de excluir a reflexão teológica do debate social. É possível postular esta proposição, pois, como visto anteriormente, a exclusão desta empobreceria ambas as áreas de saber.

Essa consciência pode ser reafirmada retomando J. Vico Peinado, pois o autor esclarece enfaticamente, que na sua maneira de perceber: "[...] me parece que hablar de bioética 'teológica' tiene sentido en cuanto manifiesta lãs señas de identidad con las que se interviene con pleno derecho en la mesa de diálogo" (VICO PEINADO, 2003, p. 459). Para reafirmar tudo isso, pode se referenciar, ainda, a proposição de que a Bioética nunca pode deixar de ser:

[...] o fruto do esforço de todos aqueles que entendem que cada novo movimento das biociências precisa ser acompanhado por um outro movimento: o da reflexão em outras áreas do conhecimento humano sobre esta mesma novidade. Cada conquista inusitada precisa ser acompanhada de uma reflexão sobre as suas consequências para a sociedade (SANCHES; SOUZA, 2008, p. 278).

Assim sendo, por ter esta responsabilidade para com a sociedade, a Bioética se vê obrigada a estar em consonância com todo o conhecimento humano, o que supõe que deve dialogar também com a Teologia, que tem muito a oferecer neste debate social, desde que esta tenha a consciência não só das suas qualidades e capacidades, mas também, de suas limitações.

Aqui se torna oportuno, para finalizar, relembrar o que postula V. Coutinho, pois para o autor, diante dessa realidade, não se pode deixar de reconhecer que a presença no debate social, tanto da parte da Bioética, como da Teologia:

[...] não pode ser descaracterizada nem invasiva, impõe-se uma análise cuidada dos dois campos (bioética e teologia), e uma reflexão crítica sobre o tipo de contributos e influências que são esperados e podem ser proporcionados. Trata-se de justificar, por um lado, a presença legítima de uma ética teológica neste debate multidisciplinar, e, por outro lado, identificar aquilo que é próprio desta presença, definindo os parâmetros e conteúdos do seu contributo neste contexto (COUTINHO, 2006, p. 193). 
Tendo a consciência, por tudo o que foi refletido, que uma reflexão bioética sem a presença da Teologia pode ser um fator de empobrecimento do debate social em questões relevantes para a sociedade, fazendo com que tanto uma como a outra área de conhecimento, deixe de crescer com as proposições próprias que surgiram nesta relação, se enfatiza o intento primeiro deste artigo: que se pode sim falar atualmente em Bioética Teológica e que esta é pertinente no debate social atual, em uma sociedade marcadamente plural e secular.

\section{Referências}

BENTO XVI. Discurso à Congregação para a Doutrina da Fé reunida em sessão plenária. 31 de Janeiro de 2008. Disponível em: <http://w2.vatican.va/content/ benedict-xvi/pt/speeches/2008/january/documents/hf_ben-xvi_spe_20080131_ dottri na-fede.html>. Acesso em: 01 dez. 2016.

COPPENS, C. Moral Principles and Medical Practice: The Basis of American Jurisprudence. New York: Benziger Brothers, 1897.

COUTINHO, V. Bioética e Teologia: a mais-valia de uma relação mútua. Didaskalia, Lisboa, v. 1, n. XXXVI, p. 191-213, jan./mar. 2006.

DE LA TORRE, J. Religiones y Bioética: ecos de una relación desde el âmbito norteamericano y mediterráneo. In: DE LA TORRE, J. (org). Veinte años de Bioética en España: memoria de una Bioética "en compañia". Madrid: Comillas, 2008. p. 12-37.

DURANT, G. Introdução Geral à Bioética: história, conceitos e instrumentos. Trad. Nicolás Nyimi Campanário. 2. ed. São Paulo: São Camilo/Loyola, 2007.

GAFO, J. ¿Bioética "Católica”? In: GAFO, J. (Ed.). Fundamentación de la Bioética y manipulación genética. Madrid: Comillas, 1988. p. 119-132.

GAFO, J. Bioética Teológica. 3 ed. Madrid: Comillas/Desclée de Brouwer, 2003.

JACOBY, G. Physician, Pastor and Patient: Problems in Pastoral Medical. New York: P. B. Hoeber, 1936.

JONSEN, A. R. The birth of Bioethics. New York: Oxford University Press, 1998. 
JONSEN, A. R. Breve historia de la ética médica. Trad. Juan Antonio Medina López. Madrid: Comillas/San Pablo, 2011.

JUNGES, J. R. Bioética: hermenêutica e casuística. São Paulo: Loyola, 2006.

MACINTYRE, A. Theology, ethics and the ethics of medicine and health care: Comments on papers by Novak, Mouw, Roach, Cahill, and Hartf. Journal of Medicine and Philosophy, Oxford, n. 4, p. 435-443, 1979.

POTTER, R. Bioética: Ponte para o future. São Paulo, Loyola, 2016.

SANCHES, M. A.; SOUZA, W. Bioética e sua relevância para a Educação. Diálogo Educacional, Curitiba, v. 8, p. 277-287, 2008.

SPERRY, W. L. Ethical Basis of Medical Care. New York: P. B. Hoeber, 1950.

VICINI, A.; KENNAN, J. F. O futuro da Bioética. Bioethikos, São Paulo, v. 5, n. 1, p. 10-20, 2011.

VICO PEINADO, J. Como hablar de "Bioética Teológica"? Moralia, Madri, v. 26, p. 439-473, 2003.

VIDAL, M. Bioética Teológica: Identidad, Epistemología y Presencia Pública. In: VELASCO, J. M. de (ed.). Bioética y Humanismo Cristiano. Bilbao: Deusto, 2011. p. 115-129. (Série Teología, 38).

Recebido: 15/05/2018

Received: 05/15/2018

Aprovado: 01/08/2018 Approved: 08/01/2018 